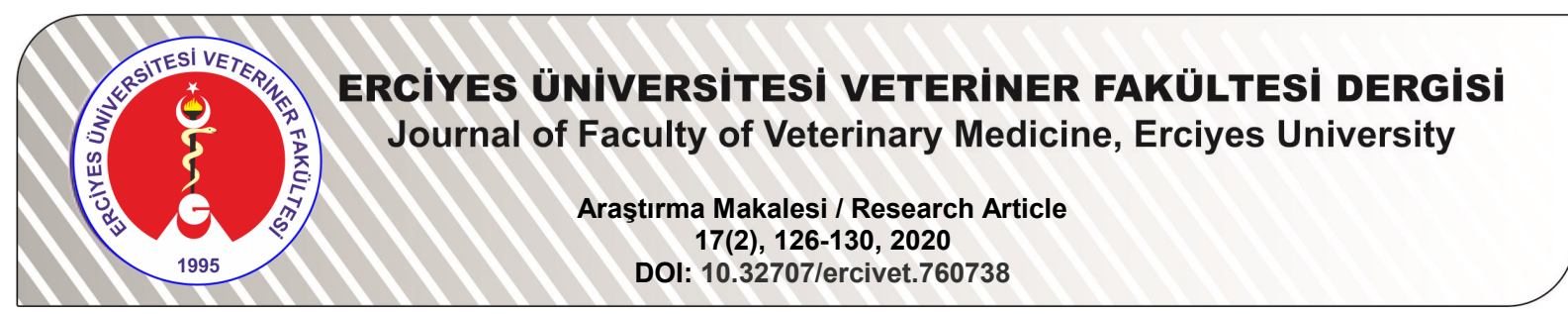

\title{
Gümüş@Grafen Oksit Nanokompozitin Biyolojik Sentezi ve Antimikrobiyal Aktivitesinin Belirlenmesi
}

\author{
Fatih Doğan KOCA
}

Erciyes Üniversitesi Veteriner Fakültesi, Su Ürünleri ve Hastalıkları ABD, Kayseri-TÜRKIYE

\begin{abstract}
Sorumlu yazar: Fatih Doğan KOCA; fatihdkoca@gmail.com; ORCID: 0000-0001-9774-3019
Atıf yapmak için: Koca FD. Gümüş@Grafen oksit nanokompozitin biyolojik sentezi ve antimikrobiyal aktivitesinin belirlenmesi. Erciyes Univ Vet Fak Derg 2020; 17(2):126-130.
\end{abstract}

\begin{abstract}
Özet: Endüstride yaygın bir şekilde kullanılan nanopartiküller (NP'ler) grafen ve kitosan gibi maddelerle modifiye edilerek hidrofilitesi ve oksidasyon kapasitesinin artması yönüyle yeni özellikler kazanabilmektedir. Bu çalışmada Syzygium aromaticum özütü ile AgNP sentezinden farklı olarak, gümüş grafen oksit nanokompozitler (Ag@GO NK) sentezlenerek karakterizasyonu değerlendirilmiştir. Elde edilen Ag@GO NK'nin Staphylococcus aureus türüne karşı antimikrobiyal aktivitesi test edilmiştir. Karakterizasyon çalışmaları sonucunda, S. aromaticum tabanlı Ag NP'lerin kısa süreli stabiliteye sahip olduğu (-16.1 mV) belirlenmiştir. Dinamik ışık saçıımı (DLS) analizi ile NP'lerin yaklaşık $327 \mathrm{~nm}$ etkin çapa sahip olduğu tespit edilmiştir. Sırayla X Işınları Toz Difraksiyon (XRD) ve Fourier Dönüşümlü Kızılötesi Spektroskopisi (FT-IR) analizi ile NP'lerin kristal yapısı ve NP sentezinde işlevsel özelliğe sahip fonksiyonel grupların varlığı gösterilmiştir. Taramalı Elektron Mikroskobu (SEM) ile Ag@GO NK'lerin morfolojileri incelenmiştir. Ag@GO NK'lerin S. aureus suşuna karşı antimikrobiyal özelliğe sahip olduğu bildirilmiştir. Çalışma, S. aromaticum tomurcuk özütü ile Ag@GO NK'lerin bioysentezi ve antimikrobiyal aktivitelerinin belirlenmesi açısından özgün ve yenilikçidir. Çalışmada elde edilen verilerin NP'lerin modifiye edilerek biyomedikal çalışmalara ışık tutacağı düşünülmektedir.

Anahtar kelimeler: Antimikrobiyal aktivite, biyolojik sentez, gümüş@grafen oksit
\end{abstract}

Biosynthesis of Silver@Graphene Oxide Nanocomposite and Determination of It's Antimicrobial Activity Abstract: Nanoparticles (NPs), which are widely used in the industry, can be modified with materials such as graphene and chitosan to gain new properties in terms of their hydrophilicity and oxidation capacity. In this study, unlike Ag NP synthesis via Syzygium aromaticum extract, silver graphene oxide nanocomposites (Ag@GO NC) were synthesized different from Ag NP synthesis via Syzygium aromaticum extract and characterized. The antimicrobial activity of Ag@GO NC against to Staphylococcus aureus was tested. As a result of characterization studies, S. aromaticum based Ag NPs have short-term stability (-16.1 mV). Dynamic light scattering (DLS) analysis showed effective diameter of NPs is approximately $327 \mathrm{~nm}$. X-Ray Diffraction (XRD) and Fourier Transform Infrared Spectroscopy (FT-IR) analysis showed that the crystalinity of NPs and the presence of functional groups in NP synthesis process, respectively. Ag@GO NCs were recorded by Scanning Electron Microscopy (SEM). Ag@GO NCs have been reported to have antimicrobial properties against $S$. aureus strain. The study is original and innovative in terms of biosynthesis and determining the antimicrobial activities of Ag@GO NCs with S. aromaticum bud extract. It is thought that the data obtained in this study will shed light on the studies in biomedical fields by modifying NPs.

Keywords: Antimicrobial activity, green sytnhesis, silver@graphene oxide

Giriş

Nanopartiküller (NP) 100 nm'den daha küçük boyuta sahip olmaları nedeni ile geniş yüzey alanlarına sahip olup atom benzeri özellikler sergilemektedir (Sangeetha ve ark., 2011). Eşsiz fiziksel ve kimyasal özellikleri ile bulk formlarından farklı özelliklere sahiptirler (Ghaedi ve ark., 2015). NP'lerin sentezinde kullanılan her bir yöntem (fiziksel, kimyasal ve biyolojik yöntemler) çeşitli avantaj ve dezavantajlara sahiptir. NP'lerin sentezinde indirgeyici ve kaplayıcı ajan olarak organik moleküllerin (enzim, polisakkarit, bitki, alg

Geliş Tarihi/Submission Date : 25.02.2020 Kabul Tarihi/Accepted Date : 09.06 .2020 ve mantar gibi) kullanılmasını içeren biyolojik sentez, ikincil bir kimyasal madde kullanılmaması ve dolayısıyla ikincil bir kimyasal atık oluşmaması, nispeten kolay ve ucuz olması özellikleri ile ilgi çekmektedir (Sintubin ve ark., 2012; Ocsoy ve ark., 2018; Strayer ve ark., 2016; Shi ve ark., 2014). Çeşitli metalik NP'ler endüstriyel olarak potansiyel uygulama alanlarına sahiptir. Gümüş $(\mathrm{Ag}) \mathrm{NP}$ lerin antikanser, antimikrobiyal, çinko oksit ( $\mathrm{ZnO}$ ) NP'lerin kozmetik ve kaplama, palladyum (Pd) NP'lerin biyokatalitik ve Altın (Au) NP'lerin DNA etiketleme alanlarında uygulanabilir olduğu bildirilmiştir (Mittal ve ark., 2013). Rhamnus virgata yaprak özütü ile sentezlenen demir oksit NP'lerin antioksidan ve antimikrobiyal aktiviteye sahip olduğu, Ruellia tuberosa yaprak özütü ile sen- 
tezlenen demir oksit NP'lerin kristal viyole boyasına karşı fotokatalitik aktivite gösterdiği, Dodonaea viscosa yaprak özütü ile sentezlenen Ag NP'lerin antimikrobiyal ve antikanser özellik sergilediği belirlenmiştir (Abbasi ve ark., 2019; Vasantharaj ve ark., 2019; Anandan ve ark., 2019).

Metalik NP'lerden Ag NP, sağlık sektörü, tekstil, sensör ve katalitik alanlarda uygulama özelliklerine sahiptir (El-Nour ve ark., 2010). Yasir ve ark., (2017) Syngonium podophyllum özütü ile sentezledikleri Ag NP'lerin antikandidal, Behravan ve ark., (2019) Berberis vulgaris özütü ile sentezledikleri Ag NP'lerin antimikrobiyal aktiviteye sahip olduğunu bildirmişlerdir. Areca catechu ve Andean Mortiño özütü ile sentezlenen Ag NP'lerin metilen mavisi boyasına karşı katalitik aktivite sergilediği kaydedilmiştir (Vinay ve Chandrasekhar 2019; Kumar ve ark., 2019).

Daha önce $S$. aromaticum yaprak ve tomurcuk özütü ile sentezlenmiş Ag NP'ler ve uygulamaları ile ilgili çok sayıda çalışmalar mevcuttur (Vijayaraghavan ve ark., 2012; Venugopal ve ark., 2017; Kaur ve ark., 2013; Rajesh ve ark., 2018; Bansal ve ark., 2018; Ajitha ve ark., 2019). Bununla birlikte başka bir çalışmada $S$. aromaticum yaprak özütü ile sentezlenen gümüş grafen oksit (Ag@GO) NK'lerin $\mathrm{Hg}^{+2}$ sensor ve katalitik etkinliği belirlenmiş olup (Sahu ve ark., 2019), S. aromaticum tomurcuk özütü ile Ag@GO NK sentezine ve antimikrobiyal etkisinin belirlenmesine yönelik bir çalışmaya rastlanmamıştır. Bu çalışmada S. aromaticum tomurcuk özütü ile ilk kez Ag@GO NK'ler çevre dostu yöntemle sentezlenerek karakterize edilmiş ve antimikrobiyal aktivitesi izlenmiştir.

\section{Gereç ve Yöntem}

\section{Ag NP'nin sentezi}

NP sentezinde indirgeyici ve kaplayıcı malzeme olarak kullanılan $S$. aromaticum ticari aktardan temin edilmiştir. Distile su ile yıkandıktan sonra etüvde 70 ${ }^{0} \mathrm{C}$ 'de kurutulmuş $S$. aromaticum örneklerinden $10 \mathrm{~g}$ alınmış ve $100 \mathrm{ml}$ distile su içerisinde bir saat süre ile demlenmiştir. Daha sonra Whatman No1 filtre kağıdı ile süzülen $10 \mathrm{ml}$ özüt, $90 \mathrm{ml} \mathrm{AgNO}_{3}$ solusyonu ile $\left(5 \times 10^{-3} \mathrm{M}\right)$ renk değişimi gözlenene kadar manyetik karıştırıcıda karıştırılarak Ag NP'ler elde edilmiş ve $\mathrm{GO}$ ile bağlanması amacıyla kullanılmıştır.

\section{Ag@GO NK'nin sentezi}

Ag@GO NK sentezi için 2 ml, 5 mM Ag NP solusyonu ve $2 \mathrm{ml} \mathrm{S}$. aromaticum özütü, $0.1 \mathrm{mg} / \mathrm{mL}(2 \mathrm{ml}$ $\mathrm{GO})$ çözeltisine eklenerek beherde manyetik karıştırı$\mathrm{Cı}$ yardımı ile karıştırılmıştır. GO ile bağlanmanın gerçekleştirilebilmesi amacıyla iki farklı $\mathrm{NaCl}$ çözeltisi hazırlanmıştır. Karışım esnasında solüsyonun üzerine $2,4 \mathrm{ml} \mathrm{NaCl}(0.09 \mathrm{M})$ eklenmiş ve hemen ardından $5 \mathrm{ml} \mathrm{NaCl}(0.29 \mathrm{M})$ çözeltisi eklenerek karıştırma işlemi yaklaşık $30 \mathrm{dk}$ devam etmiştir. Karıştırma işle- minin ardından dolusyon santrifüjlenerek $(5 \mathrm{dk}, 3000$ rpm) Ag@GO kompozitler elde edilmiştir. Sentezlenen NK'ler aynı santrifüj koşullarında distile su ile yıkanmış ve karakterizasyon çalışmalarında kullanılmak üzere muhafaza edilmiştir.

\section{Ag@GO NK'nin karakterizasyonu}

S. aromaticum özütü ile sentezlenen nano yapıların karakterizasyon çalışmaları Erciyes Üniversitesi Teknoloji Araştırma ve Uygulama Merkezi (TAUM) ve Erciyes Üniversitesi Nanoteknoloji Araştırma Merkezinde (ERNAM) gerçekleştirilmiştir. Elde edilen nano yapıların etkin çapı Dinamik ışık Saçııımı (DLS), yüzey yükü Zeta, kristal yapısı X Işınları Toz Difraksiyon (XRD), yapısına katılan organik moleküllerin varlığı Fourier Dönüşümlü Kızılötesi Spektroskopisi (FT-IR) ile belirlenmiş olup, ayrıca NK'ler SEM görüntüleri ile analiz edilmiştir.

\section{Antimikrobiyal aktivitenin belirlenmesi}

Ag@GO NK'lerin Staphylococcus aureus suşuna karşı antimikrobiyal aktivitesi disk difüzyon yöntemi ile test edilmiştir. Kısaca steril bir eküvyonla alınan koloniler $3 \mathrm{ml}$ serum fizyolojikte süspande edilerek McFarland 0.5 (108 mikroorganizma/ml)'e göre ayarlanmış disklere $25 \mu \mathrm{l}$ emdirilmiştir. Bakteriler MuellerHinton agar besiyerine ekilmiş ve kurutulan diskler $\left(37^{\circ} \mathrm{C}\right.$ 'de) agar yüzeyine yerleştirilmiştir. 24 saat inkübasyon sonrasında inhibisyon zonları belirlenmiştir.

\section{Bulgular}

\section{Ag@GO NK'nin karakterizasyonu}

Elde edilen solusyondaki Ag NP'lerin etkin çapı DLS analizi ile yaklaşık olarak $327 \mathrm{~nm}$ olarak belirlenmiş olup Şekil 1'de gösterilmiştir.

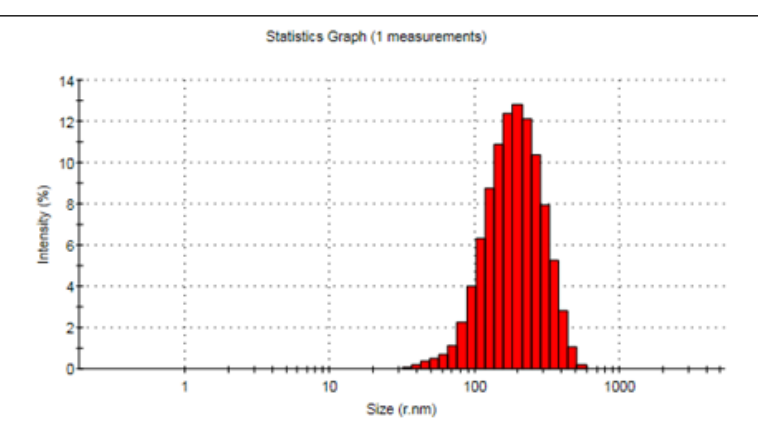

Şekil 1. Ag NP'lerin DLS analizi

S. aromaticum özütü ile sentezlenen Ag NP'lerin yüzey yükü zeta analizi ile $-16.1 \mathrm{mV}$ olarak ölçülmüştür (Şekil 2). 


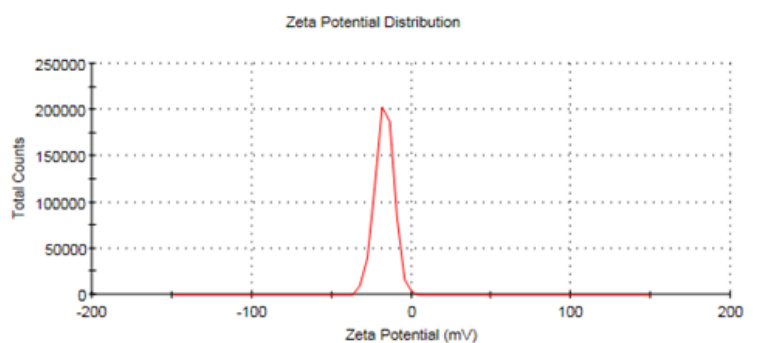

Şekil 2. Ag NP'lerin yüzey yükü

Şekil 3'te görüldüğü üzere XRD analizi ile NP'lerin yapısında $2 \theta$ düzleminde $10^{\circ}, 38^{\circ}, 44^{\circ}, 64^{\circ}$ ve $77^{\circ}$ pikler gözlenmiştir. NP'lerin yapısına katılan fonksiyonel grupların varlığı FT-IR analizinde 3415, 2923,

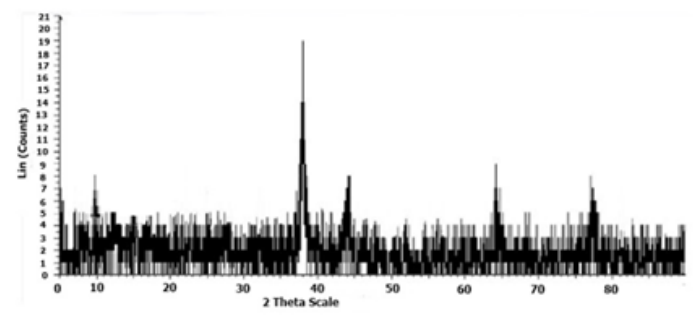

Şekil 3. Ag NP'lerin XRD analizi

2845, 1628 ve $1404 \mathrm{~cm}^{-1}$ 'de kaydedilen pikler ile belirlenmiştir (Şekil 4).

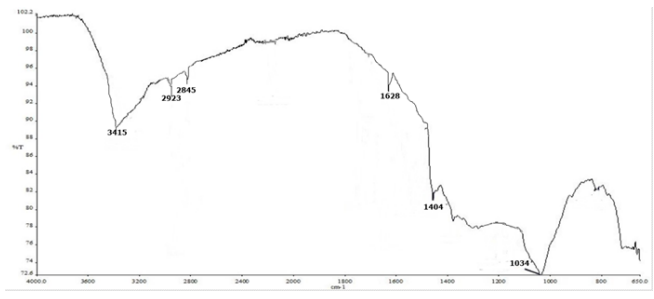

Şekil 4. Ag NP'lerin FT-IR analizi

Biyosentezi gerçekleştirilen Ag NP ve Ag@GO NK'lerin SEM analizleri sırayla Sekil 5 ve Sekil 6'da verilmiştir. Şekil 5 'ten görüleceği üzere NP'ler morfolojileri

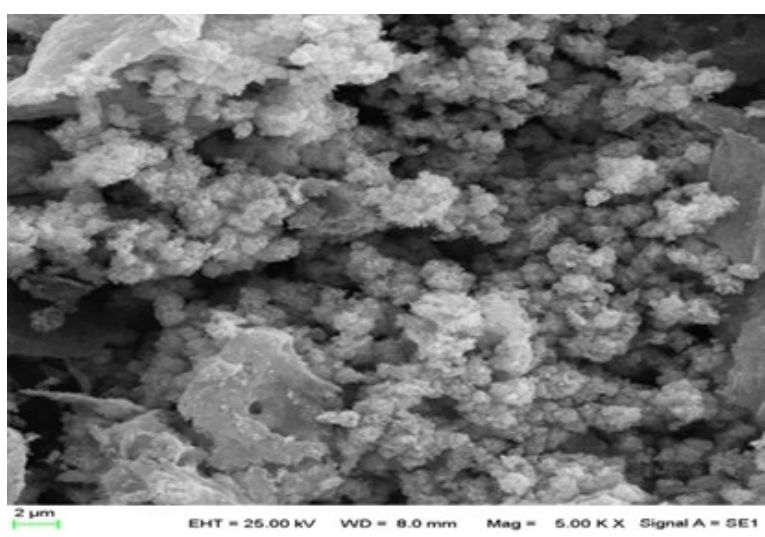

Şekil 5. Ag NP'lerin SEM resimleri

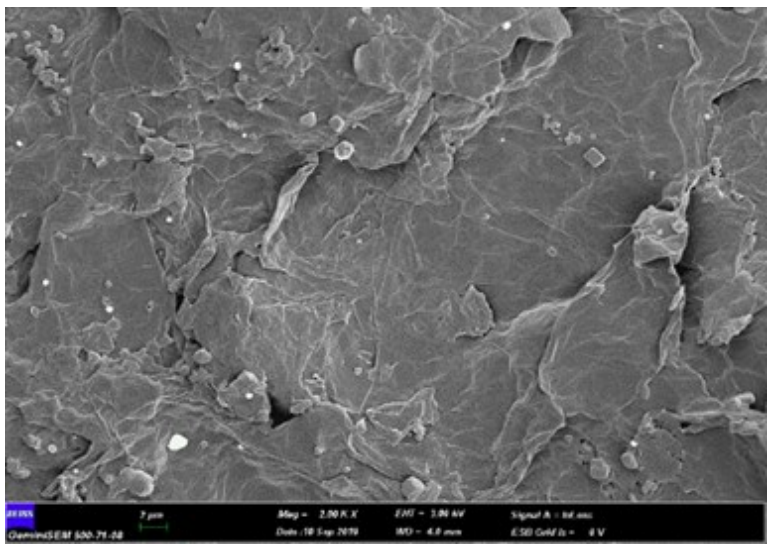

Şekil 6. Ag@GO NK'lerin SEM resimleri

yuvarlak yapıda ve yaklaşık $63 \mathrm{~nm}$ boyuta sahiptir.

\section{Ag@GO NK'nin Antimikrobiyal aktivitenin belirlenmesi}

Ag@GO NK'nin S. aureus suşuna karşı konsantrasyon bağımlı olarak antimikrobiyal aktivite sergilediği kaydedilmiştir (Şekil 7). Biyolojik sentezlenen nano boyuta sahip kompozitin $S$. aureus'a karşı minimum inhibisyon konsantrasyonu (MIC) 6.25 ppm olarak belirlenmiştir.

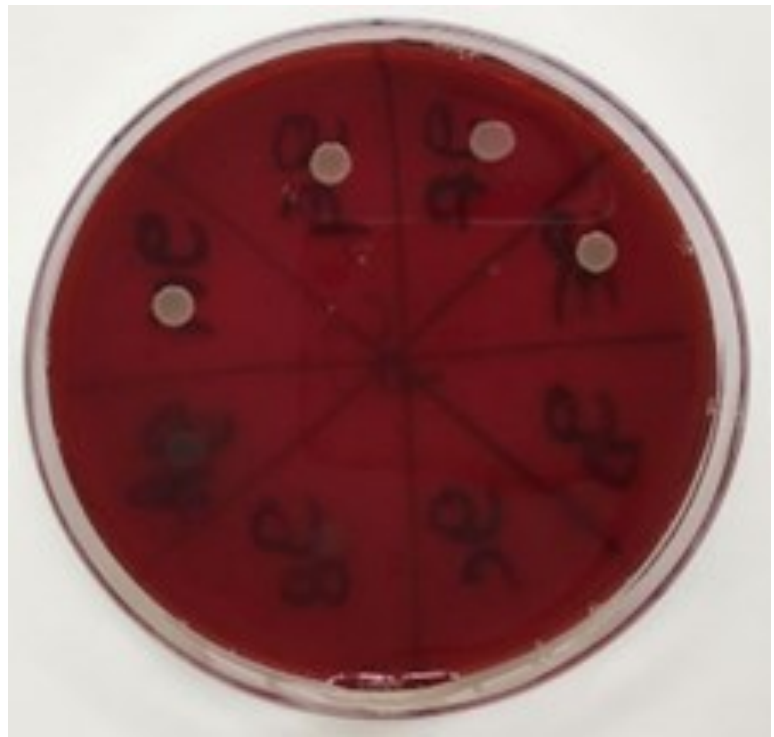

Şekil 7. Ag@GO NK'nin S. aureus suşuna karşı antimikrobiyal aktivitesi

\section{Tartışma ve Sonuç}

\section{Ag@GO NK'nin karakterizasyonu}

NP'lerin asidik ortamda sentezlenmesi neticesinde biraraya gelerek kümelenme eğiliminde oldukları ve bu nedenle etkin çaplarının yüksek olduğu bildirilmiştir (Armendariz ve ark., 2004). Daha önce bitki özütleri ile sentezlenen NP'lerin etkin çaplarının bizim veri- 
lerimizle uyumlu olduğu gözlenmiştir (Yuvakkumar ve ark., 2014). Negatif yönde düşük yüzey yükü ile partiküller arasında oluşan itme kuvveti partiküllerin kümelenmesini önlemekte olup, NP'nin kararlılığına işaret etmektedir (Sankar ve ark., 2014; Harshiny ve ark., 2015). Bu veriler ışığında sentezlenen Ag NP'nin yüzey kısa süreli kararlı yapıda olduğunu söylemek mümkündür. XRD analizi ile $2 \theta$ düzleminde gözlenen $10^{\circ}, 38^{\circ}, 44^{\circ}, 64^{\circ}$ ve $77^{\circ}$ pikleri sırasıyla (0 0

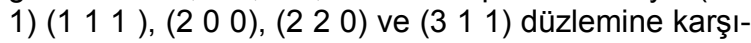
lık gelmektedir. XRD analiz ile elde edilen piklerle NK'nin yapısında Ag'nin varlığı doğrulanmış ve kristal yapısı belirlenmiştir. Çalışmamıza benzer olarak Some ve ark., (2019) ve Hsu ve Chen (2014) biyosentezini gerçekleştirdikleri Ag@GO NK'lerin kristal düzlemini (1 1111$),\left(\begin{array}{lll}2 & 0 & 0\end{array}\right),\left(\begin{array}{lll}2 & 2 & 0\end{array}\right)$ ve $\left(\begin{array}{lll}3 & 1 & 1\end{array}\right)$ olarak belirlemiş olup, çalışmamızla uyum içinde olduğu görülmüştür. S. aromaticum özütünün indirgeyici ve kaplayıcı ajan olarak kullanılması ile biyolojik olarak sentezlenen NP'lerin yapısına katılan fonksiyonel grupların varlığı FT-IR analizi ile incelenmiştir. Bu test sonucunda 3415, 1628 ve $1404 \mathrm{~cm}^{-1}$, de gözlenen pikler sırası ile alkol $(\mathrm{O}-\mathrm{H})$, alken $(\mathrm{C}=\mathrm{C})$ ve aromatik $(\mathrm{C}=\mathrm{C})$ gruplarına karşılık gelmektedir. 2923 ve $2845 \mathrm{~cm}^{-1}$ de gözlenen pikler alkan gruplarına $(\mathrm{C}-\mathrm{H})$ işaret emektedir. C-O grubunun varlığı $1034 \mathrm{~cm}^{-1}$, de gözlenen difraksiyon pik ile belirlenmiştir. SEM görüntüleri ile yuvarlak yapıda ve yaklaşık $63 \mathrm{~nm}$ boyutuna sahip olan NP'lerin kümelenme eğiliminde olduğu görülmekte olup bu durum DLS analiz verilerimizi destekler niteliktedir. Şekil 6'da AG NP'lerin GO ile bağlandığı görülmektedir. Bitki özütünün kullanılması ile elde edilen NP'lerin morfolojik özelliklerine ortam pH'ı, sıcaklık, indirgeyici ajanın ve indirgenen metalin konsantrasyonunun önemli bir role sahip olduğu daha önceki çalışmalarda gösterilmiştir (Mittal ve ark., 2013).

\section{Antimikrobiyal aktivitesinin belirlenmesi}

Biyolojik yöntemle sentezlenen Ag@Go NK'nin S. aureus'a karşı etkili bir antimikrobiyal aktivite sergilemiştir. Çeşitli metalik NP'lerin antimikrobiyal özellikleri, bakterilerin hücre duvarına bağlanması ile proteinlerin denatürasyona uğratması, membranda birikmesi ile meydana reaktif oksijen türlerinin (ROS) hücre ölümüne sebep olması ile açıklanabilmektedir (Kaur ve ark., 2013; Some ve ark., 201; Wang ve ark., 2017).

$\mathrm{Bu}$ çalışmada S. aromaticum özütü ile Ag@GO NK'lerin biyolojik sentezi, ucuz, etkili ve çevre dostu yöntemle sentezlenmiştir. Ag@GO NK'nin S. aureus suşuna karşı antimikrobiyal aktiviteye sahip olduğu belirlenmiştir. Elde edilen veriler ile bitki özütü ile sentezlenen Ag tabanlı NP'lerin kitosan ve grafen oksit gibi biyomoleküller ile modifiye edilerek oksidasyon kapasitesi ve çözünebilirliğinin artırılabileceği, ayrıca kümelenmesinin önlenebileceği düşünülmektedir.

\section{Kaynaklar}

Abbasi BA, Iqbal J, Mahmood T, vd. Biofabrication of iron oxide nanoparticles by leaf extract of Rhamnus virgata: Characterization and evaluation ofcytotoxic, antimicrobial and antioxidant potentials. Appl Organometal Chem 2019; 33: 1-15.

Ajitha B, Reddy YAK, Lee Y, Kim MJ, Ahn CW. Biomimetic synthesis of silver nanoparticles using Syzygium aromaticum (clove) extract: Catalytic and antimicrobial effects. Appl Organometal Chem 2019; 33: e4867.

Anandan M, Poorani G, Boomi P. Green synthesis of anisotropic silver nanoparticles from the aqueous leaf extract of Dodonaea viscosa with their antibacterial and anticancer activities. Process Biochem 2019; 80: 80-8.

Armendariz V, Herrera I, Peralta-Videa JR, JoseYacaman M, vd. Size controlled gold nanoparticle formation by Avena sativa biomass: use of plants in nanobiotechnology. J Nanopart Res 2004; 6 : 377-82.

Bansal H, Kaushal J, Chahar V, Shukla G, Bhatnagar A. green synthesis of silver nanoparticles using Syzygium aromaticum (clove) bud extract: Reaction optimization, characterization and antimicrobial activity. J. Bionanosci 2018; 12: 378-89.

Behravan M, Panahi AH, Naghizadeh A, vd. Facile green synthesis of silver nanoparticles using Berberis vulgaris leaf and root aqueous extract and its antibacterial activity. Int J Biol Macromol 2019; 124: $148-54$

El-Nour KMMA, Eftaiha A, Al-Warthan A, vd. Synthesis and applications of silver nanoparticles. Arab J Chem 2010; 3: 135-40.

Ghaedi M, Yousefinejad M, Safarpoor M, Zare Khafri H, Purkait MK. Rosmarinus officinalis leaf extract mediated green synthesis of silver nanoparticles and investigation of its antimicrobial properties. J Ind Eng Chem 2015; 31: 167-72.

Harshiny M, Iswarya CN, Matheswaran M. Biogenic synthesis of iron nanoparticles using Amaranthus dubius leaf extract as a reducing agent. Powder Technol 2015; 286: 744-9.

Hsu KC, Chen DH. Microwave-assisted green synthesis of $\mathrm{Ag} /$ reduced graphene oxide nanocomposite as a surface-enhanced Raman scattering substrate with high uniformity. Nanoscale Res Lett 2014; 9: 1-9.

Kaur H, Kaur S, Singh M. Biosynthesis of silver nanoparticles by natural precursor from clove and their antimicrobial activity. Biologia 2013; 68(6): 1048- 
53.

Kumar B, Vizuete KS, Sharma V, vd. Ecofriendly synthesis of monodispersed silver nanoparticles using Andean Mortiño berry as reductant and its photocatalytic activity. Vacuum 2019; 160: 272-8.

Mittal AK, Chisti Y, Banerjee UC. Synthesis of metallic nanoparticles using plant extracts. Biotechnol Adv 2013; 31: 346-56.

Ocsoy I, Tasdemir D, Mazicioglu S, vd. Biomolecules incorporated metallic nanoparticles synthesis and their biomedical applications. Mater Lett 2018; 212: 45-50.

Rajesh KM, Ajitha B, Ashok Kumar Reddy Y, Suneetha Y, Sreedhara Reddy P. Assisted green synthesis of copper nanoparticles using Syzygium aromaticum bud extract: Physical, optical and antimicrobial properties. Optik 2018; 154: 593-600.

Sahu D, Sarkar N, Sahoo G, Mohapatra P, Swain SK. Dual activities of nano silver embedded reduced graphene oxide using clove leaf extracts: $\mathrm{Hg}^{2+}$ sensing and catalytic degradation. Chem Sel 2019; 4: 2593-602.

Sangeetha G, Sivaraj R, Rajendran V. Green synthesis of zinc oxide nanoparticles by Aloe barbadensis miller leaf extract: Structure and optical properties. Mater Res Bull 2011; 46 (12): 2560-66.

Sankar R, Manikandan P, Malarvizhi V, vd. Green synthesis of colloidal copper oxide nanoparticles using Carica papaya and its application in photocatalytic dye degradation. Spectrochim Acta A 2014; 121: 746-50.

Shi H, Chen X, Lia L, vd. One-pot and one-step synthesis of bioactive urease $/ \mathrm{ZnFe}_{2} \mathrm{O}_{4}$ nanocomposites and their application in detection of urea. Dalton Trans 2014; 43: 9016-21.

Sintubin L, Verstraete W, Boon N. Biologically produced nanosilver: Current state and future perspectives. Biotechnol Bioeng, 2012; 109(10): 2422-36.

Some S, Bulut O, Biswas K, vd. Efect of feed supplementation with biosynthesized silver nanoparticles using leaf extract of Morus indica L. V1 on Bombyx mori L. (Lepidoptera: Bombycidae). Sci Rep 2019; 9: 14839.

Some S, Kumar Sen I, Mandal A, vd. Biosynthesis of silver nanoparticles and their versatile antimicrobial properties. Mater Res Express 2019; 6: 012001.

Strayer AL, Ocsoy I, Tan W, vd. Low concentrations of a silver-based nanocomposite to manage bacterial spot of tomato in the greenhouse. Plant Dis
2016; 100:1460-65

Vasantharaj S, Sathiyavimal S, Senthilkumar P, vd. Biosynthesis of iron oxide nanoparticles using leaf extract of Ruellia tuberosa: Antimicrobial properties and their applications in photocatalytic degradation. J Photoch Photobio B 2019;192: 74-82.

Venugopal K, Rather HA, Rajagopal K, vd. Synthesis of silver nanoparticles (Ag NPs) for anticancer activities (MCF 7 breast and A549 lung cell lines) of the crude extract of Syzygium aromaticum. J Photoch Photobio B 2017; 167: 282-9.

Vijayaraghavan K, Kamala Nalini SP, Udaya Prakash $\mathrm{N}$, Madhankumar D. Biomimetic synthesis of silver nanoparticles by aqueous extract of Syzygium aromaticum. Mater Lett 2012; 75: 33-35.

Vinay SP, Chandrasekhar N. Facile green chemistry synthesis of Ag nanoparticles using Areca catechu extracts for the antimicrobial activity and photocatalytic degradation of methylene blue dye. Materials Today: Proceedings 2019; 9: 499-505.

Wang L, Hu C, Shao L. The antimicrobial activity of nanoparticles: present situation and prospects for the future. Int J Nanomed 2017;12: 1227-49.

Yasir M, Singh J, Tripathi MK. vd. Green synthesis of silver nanoparticles using leaf extract of Common arrowhead houseplant and its anticandidal activity. Pharmacogn Mag 2017; 13(4): 840-44.

Yuvakkumar R, Suresh J, Nathanael AJ, Sundrarajan $\mathrm{M}$, Hong SI. Novel green synthetic strategy to prepare $\mathrm{ZnO}$ nanocrystals using rambutan (Nephelium lappaceum L.) peel extract and its antibacterial applications. Mater Sci Eng C 2014; 41: 17-27. 